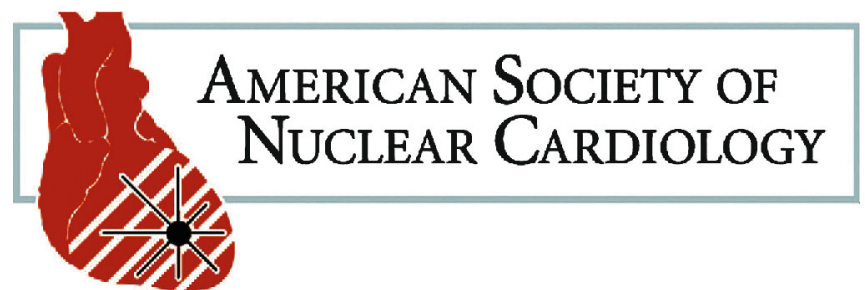

\title{
ANNOUNCEMENT
}

\section{THE JOURNAL OF NUCLEAR CARDIOLOGY IS PLEASED TO ANNOUNCE THAT WE ARE NOW OFFERING CME CREDITS TO MANUSCRIPT PEER REVIEWERS}

If a manuscript peer reviewer requests CME, submits their review within 14 days and receives a "passing" grade according to the provided criteria, they will now be able to earn CME credits. All qualified reviewers will receive an email with a link directing them to complete an evaluation and generate a CME certificate.

\section{OVERALL GOAL}

The reviewer will increase his/her skills in the peer review process thus contributing to the advancement in the field of nuclear cardiology.

\section{LEARNING OBJECTIVES}

Participants of this manuscript review activity should be able to:

- Demonstrate skills in performing critical analyses of the medical literature and knowledge of current issues and developments in nuclear cardiology.
- Conduct an appropriate review of the literature related to the proposed manuscript and, when available, a review of the evidence-based clinical data related to the proposed manuscript.

- Produce a standardized, concise, constructive and timely evaluation that is balanced and objective.

- Synthesize the review of literature with a thorough review of the proposed manuscript thereby identifying its strengths and areas needing improvement prior to publication.

\section{ACCREDITATION AND DESIGNATION STATEMENTS}

The American Society of Nuclear Cardiology (ASNC) is accredited by the Accreditation Council for Continuing Medical Education (ACCME) to provide continuing medical education for physicians.

The American Society of Nuclear Cardiology designates this manuscript review activity for a maximum of 3 AMA PRA Category 1 Credits $^{T M}$. Physicians should only claim credit commensurate with the extent of their participation in the activity.

Physicians may claim a maximum of 15 AMA PRA Category 1 Credits $^{T M}$ per year for manuscript review. 